\title{
Acquired Lightheadedness in Response to Odors After Hyperventilation
}

Ilse Van Diest, PhD, Steven De Peuter, PhD, Katrijn Piedfort, MA, Johan Bresseleers, MA, Stephan Devriese, PhD, Karel P. Van de Woestijne, MD, and Omer Van den Bergh, PhD

\begin{abstract}
Objective: This study aimed to investigate whether lightheadedness in response to odors could be acquired through previous associations with hyperventilation-induced hypocapnia. Methods: Diluted ammonia and acetic acid served as conditional odor cues (CSs) in a differential associative learning paradigm. Hyperventilation-induced hypocapnia (unconditional stimulus [US]) was used to induce lightheadedness. In a training phase, participants $(n=28)$ performed three hypocapnic and three normocapnic overbreathing trials of 60 seconds each. One odor was consistently paired with the hypocapnic overbreathing $(\mathrm{CS}+)$; the other (control) odor was paired with normocapnic overbreathing $(\mathrm{CS}-)$. In the test phase, each odor was presented once during spontaneous breathing and once during normocapnic overventilation. Lightheadedness was assessed online during each breathing trial, which was followed by an extensive hyperventilation symptom checklist. Fractional end-tidal $\mathrm{CO}_{2}$, breathing frequency, and inspiratory volume were measured throughout the experiment. Results: In the test phase, participants experienced lightheadedness more quickly in response to the odor that had been paired with hypocapnic overbreathing compared with the control odor. They also scored higher on the symptom "feeling unreal." Conclusion: Lightheadedness in response to odors can be acquired easily. The present results may help to elucidate the paradox that both avoidance and exposure to chemicals seem to be effective in reducing symptoms in idiopathic environmental illness. Key words: lightheadedness, idiopathic environmental illness, hyperventilation, conditioning, odors.
\end{abstract}

IEI = idiopathic environmental illness; NPC = neuropsychological complaints; $\mathbf{C S}=$ conditional stimulus; $\mathbf{U S}=$ unconditional stimulus; $\mathbf{T i}=$ inspiratory time; $\mathbf{T e}=$ expiratory time; $\mathbf{V i}=$ inspiratory volume; $\mathbf{V e}=$ expiratory volume; $\mathbf{F E T C O} \mathbf{O}_{2}=$ fractional end-tidal $\mathrm{CO}_{2} ; \mathbf{C B F}=$ cerebral blood flow.

\section{INTRODUCTION}

diopathic environmental illness (IEI) is an ill-defined disorder with a variety of complaints in different organ systems triggered by structurally unrelated chemicals. Among the most frequent are the neuropsychological complaints (NPC): lightheadedness, dizziness, difficulties concentrating, poor memory, fatigue, but also chest pain, shortness of breath, gastrointestinal problems, muscle and joint pain, and mood changes are frequently reported $(1,2)$. The symptoms of IEI importantly overlap with those of panic disorder (3), fibromyalgia, and chronic fatigue syndrome (4), but at least one aspect is specific for IEI: patients attribute their symptoms to chemicals in their environment. Not surprisingly, patients often reorganize their lives to avoid chemicals and rate avoidance as the most effective way to reduce symptoms (5), which seems at odds with reports showing that gradual exposure to chemicals is an effective treatment for IEI (6).

This paradox may be easily understood if one construes the development of symptoms at the onset of IEI in terms of associative (Pavlovian) learning (see also [7,8]). From that perspective, an initial toxic exposure $(9,10)$ can be considered an unconditional stimulus (US) producing symptoms, whereas the odors and other environmental cues that were present during this accident may function as conditional stimuli (CS). A similar mechanism may operate when hyperventilation and its associated symptoms are conditioned to an odor. From a learning perspec-

From the Department of Psychology (I.V.D.,S.D.P.,K.P.,J.B.,S.D., O.V.d.B.) and the Faculty of Medicine (K.P.V.d.W.), University of Leuven, Leuven, Belgium.

Address correspondence and reprint requests to Ilse Van Diest, PhD, Department of Psychology, University of Leuven, Leuven, Belgium. E-mail: Ilse.VanDiest@psy.kuleuven.be

Received for publication April 18, 2005; revision received October 21, 2005.

Dr. Van Diest is a postdoctoral researcher of the Fund of Scientific Research, Flanders, Belgium.

DOI: 10.1097/01.psy.0000204782.49159.79 tive, it can be predicted that in both scenarios, subsequent confrontations with these cues (odors) alone would be sufficient to elicit symptoms. Because patients typically avoid extended exposures to the cues (i.e., odorous chemicals), there is little chance that the learned association between the odor cues (CSs) and symptoms will extinguish.

To investigate this hypothesis, we have built a learningbased laboratory model for IEI. In the basic paradigm, a 2-minute inhalation of air enriched with $7.5 \% \mathrm{CO}_{2}$ served as US, producing symptoms such as fast breathing, smothering sensations, chest tightness, feelings of choking, pounding heart, sweating, hot flushes, lump in throat, headache, tension, and anxious feelings. An odor serving as a predictive cue was mixed with the $\mathrm{CO}_{2}$-enriched air. In control trials, another odor was mixed with regular room air. The participants received three breathing trials of each type in a training phase. In a subsequent test phase, the same set of trials was presented but this time without $\mathrm{CO}_{2}$ added to the inhaled air. Several physiological measures were taken during the trials and the intensity of the subjective symptoms was measured after each trial. Technically, this is a differential Pavlovian conditioning paradigm in which the $\mathrm{CO}_{2}$-enriched air is an US and the odors are CS. The odor mixed with $\mathrm{CO}_{2}$-enriched air is called a $\mathrm{CS}+$, whereas the odor mixed with regular room air is called a $\mathrm{CS}-$. Both odors are administered to the same subject (within-subject design), but the specific odor used in each trial type as CS+ or CS- is counterbalanced between subjects. The test phase consists of presenting both the CS+ and CS - without the US and allows assessing learning effects within subject and within odor. In a series of studies using this paradigm (see [8] for a review), we showed that participants easily learn to feel symptoms: perceiving the odor that had been associated with $\mathrm{CO}_{2}$-enriched air during the training phase induced an elevated level of symptoms compared with perceiving the control odor $(11,12)$. Learned symptoms closely resembled the symptoms induced by $\mathrm{CO}_{2}$ inhalation: the learning effects were most pronounced for respiratory symptoms (fast breathing, smothering sensations, chest tightness, feelings of choking) and did not occur for a set of "dummy" symptoms (symptoms not elicited by inhaling $\mathrm{CO}_{2}$ ). Symptom learning was typically more pronounced in participants with 


\section{ACQUIRED LIGHTHEADEDNESS IN RESPONSE TO ODORS}

elevated levels of neuroticism and in psychosomatic patients and was unrelated to changes in breathing behavior, suggesting mainly a role for perceptual-cognitive processes in symptom perception to explain the results.

Symptoms induced by an episode of $\mathrm{CO}_{2}$ inhalation may be considered a laboratory analog of a toxic accident, which is known to often precede the onset of IEI (9). However, the onset of IEI has also been found to be related to stress without a prior toxic accident (13). In addition, some patients with IEI show a reduced end-tidal $\mathrm{CO}_{2}$ in response to chemical substances $(14,15)$ suggesting a role for hyperventilation in IEI $(7,8,12,16)$. To extend our laboratory model, we wanted to test whether hyperventilation, a HYPOcapnic stimulus, could serve as an unconditional stimulus for symptom learning in response to chemicals in a similar way as $\mathrm{CO}_{2}$ inhalation, a HYPERcapnic stimulus. Hyperventilation induces hypocapnia (a lowered alveolar and arterial $\mathrm{PCO}_{2}$ ) and respiratory alkalosis, causing a multiorgan symptom pattern that often comes and goes (17). The pattern considerably overlaps with IEI and other medically unexplained functional syndromes (18).

A learning account for symptoms in response to odors based on hyperventilation as an unconditional stimulus may largely increase the ecological validity of our laboratory model for several reasons: 1) decreases in fractional end-tidal $\mathrm{CO}_{2}$ $\left(\mathrm{FETCO}_{2}\right)$ have been observed both in clinical and nonclinical samples in response to stress and anxiety (19-21). This may explain why the onset of IEI is often linked to episodes of stress, and it is consistent with finding elevated neuroticism and psychiatric comorbidity in patients with IEI;2) patients with IEI share important similarities with panic patients $(3,22)$, the symptoms of which have been linked to breathing abnormalities and hyperventilation (23-27); 3) unlike hypercapnia, hypocapnia causes vasoconstriction of the arterioles in the brain and cerebral hypoxia, which is considered responsible for the disturbance of cognitive functions and several NPC, that are prominently present in patients with IEI (28-30); and 4) it may further elucidate why exposure is an effective treatment: anticipatory stress during occasional confrontations with chemicals thought to be dangerous may trigger hyperventilation, producing the very feared symptoms and reinforcing the conviction that the chemicals are responsible, whereas extended exposures may extinguish the learned response.

The present study is the first to test the effects of experiencing a few episodes of hyperventilation-induced symptoms in association with perceiving a harmless odor on subsequent symptom reports in response to the odor only. In addition to assessing subjective symptom reports after the breathing trial like in the typical paradigm, we also wanted to closely monitor symptom changes during the trial itself. Therefore, we introduced an online rating and focused on one particular but cardinal symptom in both hyperventilation and IEI, namely lightheadedness. Other NPC and hyperventilation symptoms were assessed after the trial. Diluted ammonia and acetic acid served as conditional odor cues (CSs) in a differential associative learning paradigm. In a training phase, participants performed three hypocapnic and three normocapnic overbreathing trials of 60 seconds each. One odor was consistently paired with the hypocapnic overbreathing $(\mathrm{CS}+)$; the other (control) odor was paired with normocapnic overbreathing (CS-). In the test phase, each odor was presented once during spontaneous breathing and once during normocapnic overventilation. It was predicted that in the test phase, more NPC would occur in response to the odor that had been paired with hypocapnia compared with the control odor.

\section{METHODS \\ Participants}

Forty-one undergraduate students, aged 19 to 21 years, volunteered to participate in return for course credit or a fee of $5 €$. Because the differential conditioning paradigm requires the induction of a reliable $\mathrm{CS}+/ \mathrm{CS}-$ difference in a training phase, data from seven participants whose online lightheadedness ratings during $\mathrm{CS}+$ training trials did not exceed $10 \%$ of the lightheadedness rating during $\mathrm{CS}-$ training trials, were excluded from analyses. ${ }^{1}$ Data of six other participants were also excluded because of procedural errors $(n=2)$ or equipment failure $(n=4)$. The final dataset contained observations from 28 students (six men).

\section{Materials}

\section{Self-Report Measures}

Participants completed a custom-made checklist asking for major diseases, asthma, stuffed nose, epilepsy, hyperventilation syndrome, panic attacks, and the use of psychotropic medication. People who were positive on any of these could not participate.

During each breathing trial, participants continuously rated the level of experienced lightheadedness. To this end, participants used a dial to rate their lightheadedness online, which was fed back through a visual analog scale (VAS, range 0-100) presented on the screen of a personal computer. Specific software sampled and stored the dial's position every second.

After each breathing trial, participants completed an adapted state version of the Checklist for Psychosomatic Symptoms (31). The list was composed of symptoms belonging to one of the following subsets: paresthesia, cerebral, cardiac, gastrointestinal, respiratory, anxiety, or unclassified symptoms. To this list, we added two NPC ("lightheadedness" and "feeling unreal") and four sensations that are rarely associated with hyperventilation ("nasal congestion," "joint pain," "low back pain," and "burning eyes") to control for response biases. The latter group is further referred to as "dummy symptoms." Participants had to rate the extent to which they had felt each symptom during the past breathing trial (not at all, slightly, medium, much, or very strong).

\section{Apparatus and Physiological Recordings}

Participants breathed through a face mask (8900 Series, Hans Rudolph) that was connected to a pneumotachograph (Fleisch no. 2). Upstream from the latter device, a double one-way valve ensured separation of inspired and expired air. Expired air was sampled after but close to the expiratory valve. $\mathrm{FETCO}_{2}$ was monitored continuously by a nondispersive infrared $\mathrm{CO}_{2}$ monitor with a resolution of $1 \mathrm{~mm} \mathrm{Hg}$, an accuracy of $\pm 2 \mathrm{~mm} \mathrm{Hg}$, and a $95 \%$ response time of $125 \mathrm{~ms}$ (capnograph POET RC; Criticare). The time lag between the volume and $\mathrm{FETCO}_{2}$ signal of the POET RC was 1.3 seconds; the data collection software was programmed to synchronize both signals. The capnograph was calibrated each day using calibration gas containing $7.5 \% \mathrm{CO}_{2}$.

\footnotetext{
${ }^{1}$ Two participants breathed only very superficially during the paced breathing period. They did not comply with the experimenter's instruction to breathe deeper. As a consequence, their $\mathrm{FETCO}_{2}$ did not decrease and they did not experience any lightheadedness during the hypocapnic overbreathing in the training phase. Two other participants had very high volumes during the paced breathing period and adding $10 \% \mathrm{CO}_{2}$ to the inspired air was not sufficient to prevent their $\mathrm{FETCO}_{2}$ from decreasing during the "normocapnic" overbreathing trials. One subject felt lightheaded during the entire experiment. This person reported also having a general flu-like feeling. Two other participants did not report any lightheadedness at any trial.
} 
To maintain the $\mathrm{FETCO}_{2}$ at baseline value during normocapnic trials, a $\mathrm{CO}_{2}$-enriched air mixture $\left(10 \% \mathrm{CO}_{2}, 21 \% \mathrm{O}_{2}\right.$, and $\left.69 \% \mathrm{~N}_{2}\right)$ was manually added at the inspiratory side of the valve. In the baseline and hypocapnic overbreathing trials, compressed room air was added in a similar way to prevent the sound produced by the decompression of the $\mathrm{CO}_{2}$ mixture would function as a discriminative stimulus for the nonoccurrence of lightheadedness. The $\mathrm{CO}_{2}$ mixture and the compressed regular air were stored in standard gas cylinders.

A Labmaster card and a PC processed the volume signals from the pneumotachograph and the $\mathrm{FETCO}_{2}$ signals from the capnograph with a sampling rate of $20 \mathrm{~Hz}$. They were plotted as a function of time and visually inspected for technical abnormalities and movement artifacts. Specific software extracted pauses and breathing irregularities and determined the following parameters for each breath: inspiratory (Ti) and expiratory time (Te) in seconds, inspiratory (Vi) and expiratory volume (Ve) in milliliters, inspiratory drive in milliliters per second, and percentage of end-tidal $\mathrm{CO}_{2}\left(\mathrm{FETCO}_{2}\right)$. Irregular and shallow breaths not reaching an end-tidal alveolar plateau were rejected from analysis. Because Vi and Ve did not differ, only Vi is reported.

Odors were vaporized using a Devilbiss Nebulizer 646 and led to the mask through a small vinyl tube. Because differences in subjective saliency of conditional stimuli are known to influence associative learning, we equalized the subjective saliency ratings of both odors (pilot data) by dispersing acetic acid $\left(5 \%\right.$ dissolved in $\left.\mathrm{H}_{2} \mathrm{O}\right)$ at a higher rate $(4.5 \mathrm{~L} / \mathrm{min})$ than ammonia $(0.8 \%$ in $\mathrm{H}_{2} \mathrm{O}$, dispersed at $2 \mathrm{~L} / \mathrm{min}$ ). Because these differential dispersion rates led to a different amount of regular air mixed into the expired air in acetic acid as opposed to ammonia trials, an offline procedure was applied to correct the underestimation of the $\mathrm{FETCO}_{2}$ levels during trials with acetic acid (see Appendix).

\section{Procedure}

The study was approved by the ethical committee of the Faculty. Data were collected in January 2003.

On arrival, the participants read a cover story, explaining that the experiment aimed to understand why many people working in air-conditioned environments regularly complain from lightheadedness. The story suggested that such lightheadedness may come from the cleaning products used to maintain air-conditioning systems and that the present experiment would investigate whether direct inhalation of two of the most commonly used cleaning products would produce lightheadedness in a young and healthy, nonworking population. To this end, participants were asked to inhale such products through a face mask. The use of the VAS was explained, and it was said that "zero" represented no lightheadedness, whereas "100" represented the strongest lightheadedness one could ever experience. It was assured that the products were not harmful but that transient lightheadedness or other symptoms could occur during inhalation. It was also explained that the products would have a particular, distinctive odor. Finally, the text read that they would be asked to breathe spontaneously in some trials and to breathe deeply on the rhythm of a metronome in other trials.

After having read the cover story, it was explained that the experiment consisted of two series of seven and five breathing trials. A breathing trial implied breathing through the face mask for 1 minute and rating the experienced lightheadedness continuously. After each breathing trial, the face mask was to be put off for 5 minutes during which the hyperventilation symptom checklist was filled out. Before both the training and test phases, there was a baseline trial in which spontaneous breathing was recorded and no odors were administered. A summary of the design is shown in Figure 1.

The training phase consisted of six overbreathing trials presented in a semirandomized order: one odor was paired three times with hypocapnic overbreathing $(3 \times \mathrm{CS}+$ trial $)$, whereas the other odor was paired three times with normocapnic overbreathing $(3 \times \mathrm{CS}-$ trial $)$. Participants were instructed to breathe as deeply as possible on the rhythm of the metronome ( 30 breaths a minute) while the experimenter actively coached the participants to keep up with the pace of the metronome. In the normocapnic trials (CS - trials), the experimenter maintained the normocapnic level during overbreathing by adding a $10 \% \mathrm{CO}_{2}$ mixture into the inspired air. The target value was set at the participant's mean $\mathrm{FETCO}_{2}$ during the baseline trial preceding the training phase. Thirteen participants received ammonia as CS + and acetic acid as CS - and vice versa for the other 15 participants. No more than two trials of the same type $(\mathrm{CS}+$ or $\mathrm{CS}-$ ) followed each other, resulting in 14 possible $\mathrm{CS}+/ \mathrm{CS}-$ order sequences for the six training trials. Each of these order sequences was applied to two participants. A 15-minute pause followed the training phase. After the pause, a second baseline trial was run.

The test phase consisted of 4 trials: each odor $(\mathrm{CS}+/ \mathrm{CS}-)$ was presented once during spontaneous breathing and once during normocapnic overventilation. Half of the participants received the spontaneous breathing trials first, whereas the other half received the overbreathing trials first. Also, half of the participants received $\mathrm{CS}+$ first (both during spontaneous breathing and overbreathing), whereas the other half received CS - first. This resulted in four possible order sequences for the test phase. Seven participants were randomly assigned to each of the four order sequences of the test phase. After the end of the experiment, participants were debriefed.

\section{Data Reduction and Analysis}

The time (in seconds) elapsed before the first lightheadedness (any change from zero) was experienced (or TEBL) during a trial was derived from the online measurement. A second measure was the intensity of the experienced lightheadedness, operationalized as the mean of all lightheadedness ratings $>0$.

The ratings for the items "lightheadedness," "feeling unreal," and "dizziness" from the symptom checklist were analyzed individually. For the remaining symptoms of the checklist, sum scores of subgroups of symptoms were calculated and analyzed: anxiety, gastrointestinal, respiratory, cardiac, paresthesia, unclassified, and dummy symptoms. Means per trial of the following respiratory parameters were calculated and analyzed: inspiratory (Ti) and expiratory (Te) time, inspiratory volume (Vi), and $\mathrm{FETCO}_{2}$.

Baseline, training and test trials were analyzed separately. The former were analyzed in a mixed analysis of variance (ANOVA) with CS + odor (ammonia/acetic acid) as a between-subject variable and phase (training/test) as a within-subject variable. Result of these ANOVAs on baseline trials are only reported when significant effects showed up. The six overbreathing trials during training were analyzed in a CS + odor (ammonia/acetic acid) $\times \mathrm{CS}$ $(\mathrm{CS}+/ \mathrm{CS}-) \times$ trial (first/second/third) design. Only $\mathrm{CS}+$ odor was a between-subject variable. Greenhouse-Geisser corrections were applied for all effects involving trial as a variable. The four test trials were analyzed in an ANOVA with CS + odor (ammonia/acetic acid) as between-subject variable and CS (+/-) and breathing (spontaneous/normocapnic overbreathing) as within-subject variables. Respiratory data from the test trials were analyzed separately for overbreathing and spontaneous breathing trials in ANOVAs with CS + odor (ammonia/acetic acid) as between-subject variable and CS $(+/-)$ as within-subject variable. Because they are our primary measures, we report all statistics for TEBL and intensity. Not to overload the result section, we report only significant effects for symptoms assessed after each trial and for respiratory measures. $\alpha$ was set at 0.05 . Effect sizes of significant effects were calculated using $f^{2}(32,33)$, a statistic estimating the proportions of variability in the criterion variable as additional sources of variance are taken into account. Values of $0.02,0.15$, and 0.35 are considered as small, medium, and large, respectively (33).

\begin{tabular}{|c|c|c|c|c|c|c|c|c|}
\hline Baseline & \multicolumn{2}{|c|}{ Training phase } & \multirow[t]{2}{*}{ Pause } & Baseline & \multicolumn{4}{|c|}{ Test phase } \\
\hline $\begin{array}{c}\text { No odor } \\
\text { Spontaneous } \\
\text { Breathing }\end{array}$ & $\begin{array}{c}\text { CS+ } \\
\text { Hypocapnic } \\
\text { Overbreathing } \\
3 x\end{array}$ & $\begin{array}{c}\text { CS- } \\
\text { Normocapnic } \\
\text { Overbreathing } \\
3 x\end{array}$ & & $\begin{array}{c}\text { No odor } \\
\text { Spontaneous } \\
\text { Breathing }\end{array}$ & $\begin{array}{c}\text { CS+ } \\
\text { Spontaneous } \\
\text { Breathing }\end{array}$ & $\begin{array}{c}\text { CS- } \\
\text { Spontaneous } \\
\text { Breathing }\end{array}$ & $\begin{array}{c}\text { CS+ } \\
\text { Normocapnic } \\
\text { Overbreathing }\end{array}$ & $\begin{array}{c}\text { CS- } \\
\text { Normocapnic } \\
\text { Overbreathing }\end{array}$ \\
\hline & \multicolumn{2}{|c|}{ Semi-randomized } & & & \multicolumn{4}{|c|}{ Semi-randomized } \\
\hline
\end{tabular}

Figure 1. Study design. 


\section{ACQUIRED LIGHTHEADEDNESS IN RESPONSE TO ODORS}

Finally, correlations between $\mathrm{FETCO}_{2}$ and measures of lightheadedness (TEBL, intensity, and lightheadedness rated after the trial) during the training and the test phase were calculated, as well as the correlations among the three measures of lightheadedness.

\section{RESULTS}

\section{Training}

\section{Time Elapsed Before Lightheadedness}

Participants experienced sooner lightheadedness during $\mathrm{CS}+$ as compared with $\mathrm{CS}-$ training trials $(F[1,26]=19.43$, $p<.01, f^{2}=0.11$, see Table 1$)$. Main effects and two-way interactions involving $\mathrm{CS}+$ odor or trial were not significant $(\mathrm{CS}+$ odor: $F[1,26]=0.75$, not significant $[\mathrm{NS}]$; trial: $F[2$, $52]=2.40, \mathrm{NS}, \epsilon=0.80 ; \mathrm{CS}+$ odor $\times \mathrm{CS}: F[1,26]=0.03$, $\mathrm{NS}$; CS + odor $\times$ trial: $F[2,52]=0.03, \mathrm{NS}, \epsilon=0.80 ; \mathrm{CS} \times$ trial: $F[2,52]=1.81, \mathrm{NS}, \epsilon=0.80)$. A significant three-way interaction among $\mathrm{CS}+$ odor, $\mathrm{CS}$, and trial was observed $(F$ $\left.[2,52]=3.47, p<.05, \epsilon=0.80, f^{2}=0.02\right)$. For participants receiving ammonia as the $\mathrm{CS}+$ odor, TEBL of the first $\mathrm{CS}+$ trial was not different from the first CS - trial $(F[1,26]=$ $0.31, \mathrm{NS})$. In subsequent trials, TEBL for $\mathrm{CS}+$ trials was shorter than for CS - trials $(F[1,26]=11.93, p<.01$ and $F[1,26]=$ $8.65, p<.01$, for trials 2 and 3 , respectively). Another pattern was found for the group who received acetic acid as $\mathrm{CS}+$. For this group, TEBL for CS + was shorter than for CS - in trial 1 ( $F$ $[1,26]=3.97, p<.05)$ and in trial $3(F[1,26]=19.06, p<$ $.01)$, but not in trial $2(F[1,26]=0.95, \mathrm{NS})$.

\section{Intensity}

Participants experienced more intense lightheadedness during $\mathrm{CS}+$ as compared with $\mathrm{CS}-$ training trials $(F[1,26]=$
53.82, $p<.01, f^{2}=0.18$, see Table 1). Main effects or two-way interactions involving $\mathrm{CS}+$ odor or trial were not significant $(\mathrm{CS}+$ odor: $F[1,26]=0.03$, NS; trial: $F[2,52]=$ $2.25, \mathrm{NS}, \epsilon=0.94$; CS + odor $\times \mathrm{CS}: F[1,26]=3.12, \mathrm{NS}$; $\mathrm{CS}+$ odor $\times$ trial: $F[2,52]=1.14, \mathrm{NS}, \epsilon=0.94$; $\mathrm{CS} \times$ trial: $F[2,52]=2.24, \mathrm{NS}, \epsilon=0.94)$. A significant $\mathrm{CS}+$ odor $\times$ $\mathrm{CS} \times$ trial interaction was present $(F[2,52]=4.41, p<.05$, $\epsilon=0.94, f^{2}=0.02$ ). A pattern of results similar to that for TEBL emerged from the follow-up comparisons of this interaction. For people who received ammonia as $\mathrm{CS}+$ odor, a significant $\mathrm{CS}+/ \mathrm{CS}-$ difference was present in trial 2 ( $F[1$, $26]=45.82, p<.01)$ and in trial $3(F[1,26]=20.45, p<$ $.01)$, but not in trial $1(F[1,26]=1.51, \mathrm{NS})$. For the other group, a significant $\mathrm{CS}+/ \mathrm{CS}-$ difference was present for trial $1(F[1,26]=4.60, p<.05)$ and trial $3(F[1,26]=16.44$, $p<.01)$, but not for trial $2(F[1,26]=0.27, \mathrm{NS})$.

\section{Symptoms Assessed After the Breathing Trial}

During the training phase, participants reported more "lightheadedness" $\left(F[1,26]=30.27, p<.01, f^{2}=0.16\right)$, "dizziness" $\left(F[1,26]=28.94, p<.05, f^{2}=0.28\right)$, and "feeling unreal" $\left(F[1,26]=5.75, p<.05, f^{2}=0.05\right)$ for $\mathrm{CS}+$ than for CS trials (Table 1). Except for dummy and gastrointestinal symptoms, all scores on the symptom subgroups were higher for $\mathrm{CS}+$ as compared with $\mathrm{CS}-$ training trials: anxiety $(F[1$, $\left.26]=13.93, p<.01, f^{2}=0.06\right)$, respiratory $(F[1,26]=$ 4.62, $\left.p<.05, f^{2}=0.01\right)$, cardiac $(F[1,26]=6.41, p<.05$, $\left.f^{2}=0.03\right)$, paresthesia $\left(F[1,26]=8.09, p<.05, f^{2}=0.03\right)$, and unclassified $\left(F[1,26]=4.96, p<.05, f^{2}=0.007\right)$ (see Table 1). Unclassified and dummy symptom scores increased

TABLE 1. Means (Standard Deviations) of Symptoms and Respiration During the Training Phase $(n=28)$

\begin{tabular}{|c|c|c|c|c|c|c|c|}
\hline & \multirow[b]{2}{*}{ Baseline } & \multicolumn{2}{|c|}{ Trial 1} & \multicolumn{2}{|c|}{ Trial 2} & \multicolumn{2}{|c|}{ Trial 3} \\
\hline & & $\mathrm{CS}+$ & CS- & $\mathrm{CS}+$ & CS- & $\mathrm{CS}+$ & CS- \\
\hline Intensity & $5.20(9.64)$ & $21.19(15.81)$ & $11.34(15.39)$ & $28.50(20.77)$ & $13.70(21.58)$ & $31.71(21.89)$ & $11.43(15.10)$ \\
\hline TEBL & $43.43(18.64)$ & $36.21(16.61)$ & $42.71(17.19)$ & $30.25(16.42)$ & $41.28(21.18)$ & $26.14(14.28)$ & $40.32(18.10)$ \\
\hline \multicolumn{8}{|l|}{$\begin{array}{l}\text { Symptoms } \\
\text { posttrial }\end{array}$} \\
\hline Dizziness & $0.39(0.57)$ & $1.68(0.82)$ & $0.68(0.14)$ & $1.86(0.93)$ & $0.86(0.93)$ & $1.82(1.39)$ & $0.90(0.83)$ \\
\hline F unreal & $0.00(0.00)$ & $0.29(0.60)$ & $0.04(0.04)$ & $0.39(0.63)$ & $0.21(0.79)$ & $0.39(0.74)$ & $0.11(0.31)$ \\
\hline Anxiety & $0.61(0.92)$ & $1.32(1.42)$ & $0.68(1.02)$ & $0.96(1.14)$ & $0.68(1.44)$ & $1.36(1.68)$ & $0.46(0.96)$ \\
\hline Paresth & $0.14(0.76)$ & $0.82(1.54)$ & $0.50(1.40)$ & $1.50(2.13)$ & $0.57(1.37)$ & $1.50(2.43)$ & $0.82(1.74)$ \\
\hline Respir & $0.64(0.91)$ & $3.11(2.17)$ & $2.36(2.36)$ & $3.04(2.60)$ & $3.04(3.45)$ & $3.39(3.96)$ & $2.25(3.42)$ \\
\hline Cardiac & $0.64(0.91)$ & $2.68(2.97)$ & $1.46(1.84)$ & $2.50(3.05)$ & $2.18(3.15)$ & $3.36(4.26)$ & $1.75(2.65)$ \\
\hline \multicolumn{8}{|l|}{ Respiration } \\
\hline $\mathrm{FETCO}_{2}$ & $4.76(0.53)$ & $3.66(0.47)$ & $5.04(0.63)$ & $3.26(0.45)$ & $4.74(0.56)$ & $3.19(0.42)$ & $4.73(0.60)$ \\
\hline $\mathrm{Vi}$ & $753 \quad(256)$ & 1388 & 1355 & 1666 & 1565 & 1698 & 1635 \\
\hline $\mathrm{Ti}$ & $1.81(0.97)$ & $0.99(0.09)$ & $1.02(0.13)$ & $1.01(0.12)$ & $0.99(0.11)$ & $1.01(0.11)$ & $1.01(0.11)$ \\
\hline $\mathrm{Te}$ & $2.27(0.64)$ & $1.09(0.10)$ & $1.10(0.14)$ & $1.08(0.11)$ & $1.07(0.10)$ & $1.09(0.10)$ & $1.09(0.10)$ \\
\hline
\end{tabular}

LH = lightheadedness; TEBL $=$ time elapsed before lightheadedness; $\mathrm{F}$ unreal $=$ feeling unreal; Paresth $=$ paresthesia; Respir $=$ respiratory; $\mathrm{GI}=$ gastrointestinal; Unclas = unclassified; $\mathrm{FETCO}_{2}=$ fractional end-tidal $\mathrm{CO}_{2} ; \mathrm{Vi}=$ inspiratory volume; $\mathrm{Ti}=$ inspiratory time; Te $=$ expiratory time. 


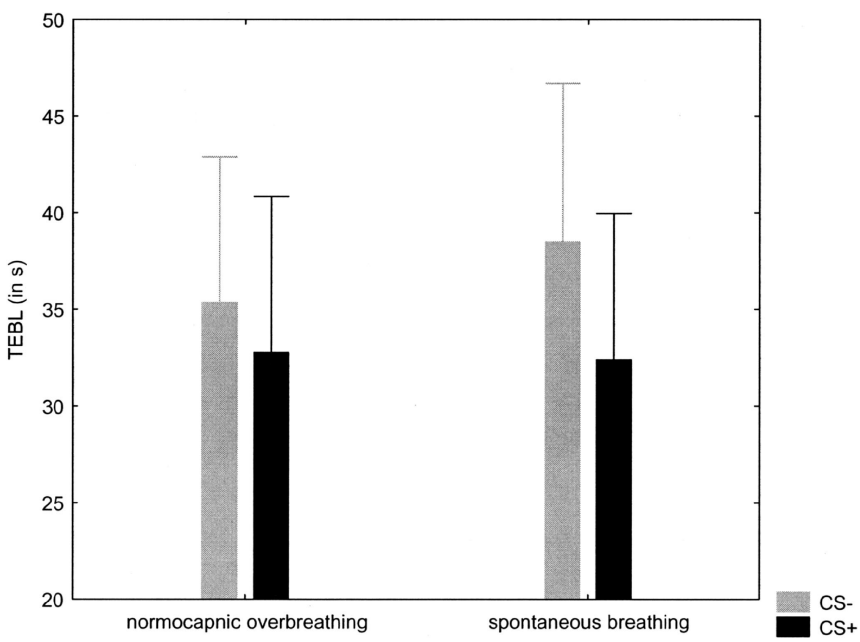

Figure 2. Mean time (in seconds) elapsed before lightheadedness showing up during the test phase for $\mathrm{CS}+$ and $\mathrm{CS}-$ trials during spontaneous breathing and normocapnic overventilation. Bars denote $95 \%$ confidence intervals.

over training trials $\left(F[2,52]=7.19, p<.05, \epsilon=0.62, f^{2}=\right.$ 0.03 and $F[2,52]=4.34, p<.05, \epsilon=0.67, f^{2}=0.02$, respectively).

\section{Respiration}

$\mathrm{FETCO}_{2}$ was lower during $\mathrm{CS}+$ than during $\mathrm{CS}-$ training trials, indicating that the normocapnic overbreathing as a within-subject control was successful $(F[1,26]=386.01$, $p<.01, f^{2}=1.97$, see Table 1$)$. Also, $\mathrm{FETCO}_{2}$ was significantly higher during the first than during the second and third training trial $\left(F[2,52]=19.36, p<.01, \epsilon=0.78, f^{2}=0.11\right.$; Tukey HSD test, both $p<.01$, see Table 1). A similar effect was present for Vi: participants breathed not as deep during the first as compared with the second and the third training trials $\left(F[2,52]=20.80, p<.05, \epsilon=0.78, f^{2}=0.07\right.$; Tukey HSD test, both $p<.01$, see Table 1). No significant effects were observed for $\mathrm{Ti}$ or for $\mathrm{Te}$.

\section{Test \\ Time Elapsed Before Lightheadedness}

A significant learning effect was found for TEBL. Participants reported lightheadedness more rapidly during $\mathrm{CS}+$ than during $\mathrm{CS}-$ trials $\left(F[1,26]=4.93, p<.05, f^{2}=0.01\right.$; means [standard deviations] were 32 [18] s and 37 [18] s, respectively, see Fig. 2 and Table 2). All other main and interaction effects were not significant $(\mathrm{CS}+$ odor: $F[1,26]=$ 0.03, NS; breathing: $F[1,26]=0.27, \mathrm{NS}$; $\mathrm{CS}+$ odor $\times \mathrm{CS}$ : $F[1,26]=0.32$, NS; CS + odor $\times$ breathing: $F[1,26]=0.02$, NS; CS $\times$ breathing: $F[1,26]=1.19, \mathrm{NS}$; $\mathrm{CS}+$ odor $\times \mathrm{CS} \times$ breathing: $F[1,26]=3.85$, NS).

\section{Intensity}

No significant effects were present for intensity (CS: $F[1$, $26]=0.01, \mathrm{NS}$; CS + odor: $F[1,26]=0.18, \mathrm{NS}$; breathing: $F[1,26]=0.20, \mathrm{NS} ; \mathrm{CS}+$ odor $\times \mathrm{CS}: F[1,26]=0.28, \mathrm{NS}$; $\mathrm{CS}+$ odor $\times$ breathing: $F[1,26]=0.27, \mathrm{NS}$; $\mathrm{CS} \times$ breathing: $F[1,26]=0.43, \mathrm{NS}$; $\mathrm{CS}+$ odor $\times \mathrm{CS} \times$ breathing: $F[1$, $26]=0.93, \mathrm{NS})$.

\section{Symptoms Assessed After the Breathing Trial}

A significant learning effect was found for the posttrial ratings on the item "feeling unreal" $(F[1,26]=4.28, p<.05$,

TABLE 2. Means (Standard Deviations) of Symptoms and Respiration During the Test Phase $(n=28)$

\begin{tabular}{|c|c|c|c|c|c|}
\hline & Baseline & \multicolumn{2}{|c|}{ Normocapnic Overbreathing } & \multicolumn{2}{|c|}{ Spontaneous Breathing } \\
\hline \multicolumn{6}{|l|}{ LH_online } \\
\hline Intensity & $6.33(10.93)$ & $15.64(16.29)$ & $13.41(13.52)$ & $14.69(16.44)$ & $16.42(24.72)$ \\
\hline TEBL & $44 \quad(19)$ & $33 \quad(20)$ & $36 \quad(19)$ & 33 (19) & $38 \quad(21)$ \\
\hline \multicolumn{6}{|c|}{ Symptoms posttrial } \\
\hline F unreal & $0.00(0.00)$ & $0.21(0.79)$ & $0.04(0.19)$ & $0.14(0.49)$ & $0.04(0.19)$ \\
\hline Anxiety & $0.11(0.42)$ & $0.36(0.87)$ & $0.29(0.66)$ & $0.21(0.50)$ & $0.00(0.00)$ \\
\hline Paresth & $0.14(0.76)$ & $0.46(0.96)$ & $0.46(1.62)$ & $0.43(1.35)$ & $0.32(0.95)$ \\
\hline Respir & $0.32(0.86)$ & $2.86(3.18)$ & $2.68(3.75)$ & $1.00(2.29)$ & $0.82(1.91)$ \\
\hline Cardiac & $0.57(1.82)$ & $1.29(1.90)$ & $1.04(1.67)$ & $1.07(1.63)$ & $1.25(1.69)$ \\
\hline GI & $0.11(0.42)$ & $0.68(1.22)$ & $0.54(0.67)$ & $0.46(0.92)$ & $0.29(0.85)$ \\
\hline $\mathrm{FETCO}_{2}$ & $4.78(0.54)$ & $4.61(0.44)$ & $4.68(0.48)$ & $4.76(0.55)$ & $4.80(0.49)$ \\
\hline $\mathrm{Vi}$ & $909 \quad(326)$ & 1756 & $1695 \quad(506)$ & $823 \quad(364)$ & $811 \quad(310)$ \\
\hline $\mathrm{Ti}$ & $1.89(1.02)$ & $0.99(0.12)$ & $0.99(0.10)$ & $1.72(0.54)$ & $1.76(0.61)$ \\
\hline $\mathrm{Te}$ & $2.24(0.71)$ & $1.10(0.08)$ & $1.09(0.10)$ & $2.10(0.68)$ & $2.09(0.62)$ \\
\hline
\end{tabular}

$\mathrm{LH}=$ lightheadedness; TEBL $=$ time elapsed before lightheadedness; $\mathrm{F}$ unreal $=$ feeling unreal; Paresth = paresthesia; Respir $=$ respiratory; GI $=$ gastrointestinal; Unclas = unclassified; $\mathrm{FETCO}_{2}=$ fractional end-tidal $\mathrm{CO}_{2} ; \mathrm{Vi}=$ inspiratory volume; $\mathrm{Ti}=$ inspiratory time; Te $=$ expiratory time. 


\section{ACQUIRED LIGHTHEADEDNESS IN RESPONSE TO ODORS}

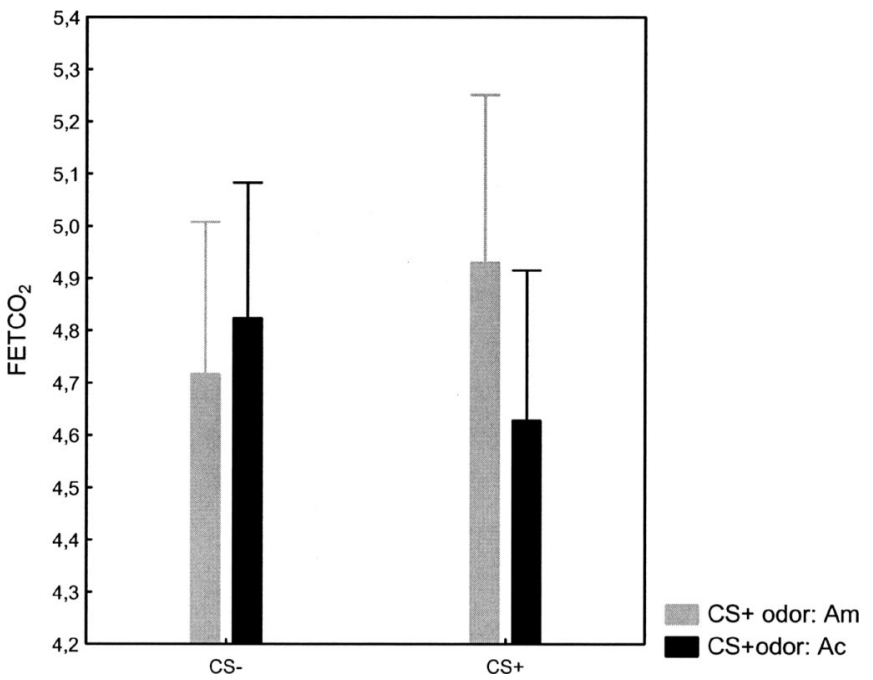

Figure 3. Mean fractional end-tidal $\mathrm{CO}_{2}$ during spontaneous breathing trials of the test phase for each CS + odor group. Bars denote $95 \%$ confidence intervals.

$\left.f^{2}=0.03\right)$ but not for "lightheadedness" $(F[1,26]=0.32$, NS) or for "dizziness" $(F[>1,26]=2.93, \mathrm{NS})$.

No learning effects were found for any subgroup of symptoms. Participants reported more respiratory symptoms for the normocapnic overbreathing trials than for the trial in which they could breathe spontaneously $(F[1,26]=12.01, p<.05$, $\left.f^{2}=0.11\right)$. For symptoms of paresthesia, the training effects interacted with the particular odor that served as CS $+(F[1$, $\left.26]=4.43, p<.05, f^{2}=0.01\right)$. Follow-up comparisons indicated that there was a tendency to experience more symptoms of paresthesia toward the CS + than the CS - for the group who received acetic acid as the CS + odor $(F[1,26]=$ $3.47, p<.08)$. This effect was not significant for the group who received ammonia as CS + odor $(F[1,26]=1.31$, NS $)$.

\section{Respiration}

No significant effects of CS + odor or of CS were observed on any parameter for the normocapnic overbreathing trials of the test phase. For the spontaneous breathing trials, a significant CS+ odor $\times \mathrm{CS}$ interaction was found for $\mathrm{FETCO}_{2}$ (see Fig. 3) $\left(F[1,25]=12.41, p<.01, f^{2}=0.04\right)$, whereas $\mathrm{FETCO}_{2}$ during $\mathrm{CS}+$ was higher than during $\mathrm{CS}-$ for participants who received ammonia as CS+ odor $(F[1,25]=$ $6.08, p<.05)$, a trend toward the opposite pattern was observed for participants receiving acetic acid as CS+ odor $(F$ $[1,26]=6.38, p<.06)$. Although only marginally significant, corresponding patterns were found for $\operatorname{Ti}(F[1,25]=$ $3.75, p=.06, f^{2}=0.01$; see Fig. $\left.4 \mathrm{~A}\right)$ and for Te $(F[1,25]=$ $3.74, p=.06, f^{2}=0.01$ (see Fig. 4B); participants tended to breathe faster during $\mathrm{CS}+$ than $\mathrm{CS}-$ trials if acetic acid served as CS+ odor and inversely if ammonia was CS+ odor. For inspiratory volume, no effects were observed.

\section{Correlations}

Both during the training and the test phases, TEBL was negatively correlated with intensity (training: $r=-0.61, p<$ $.01, n=168$; test: $r=-0.67, p<.01, n=112)$ as well as with lightheadedness rated posttrial (training: $r=-0.48, p<$ $.01, n=168$; test: $r=-0.46, p<.01, n=112$ ). Intensity and lightheadedness rated posttrial were positively associated in both phases of the experiment (training: $r=0.69, p<.01$, $n=168$; test: $r=0.58, p<.01, n=112$ ).

During the training phase, a lower $\mathrm{FETCO}_{2}$ was related to more lightheadedness posttrial ( $r=-0.27, p<.01, n=168$ ), to more intense online lightheadedness $(r=-0.34, p<.01, n=$ 168), and to shorter TEBLs $(r=0.24, p<.01, n=168)$. No significant correlations between $\mathrm{FETCO}_{2}$ and the lightheadedness measures were present in the test phase (for TEBL: $r=$ -0.02 , NS, $n=168$; for intensity: $r=-0.05$, NS, $n=168$; lightheadedness rated posttrial: $r=0.05$, NS, $n=168$ ).

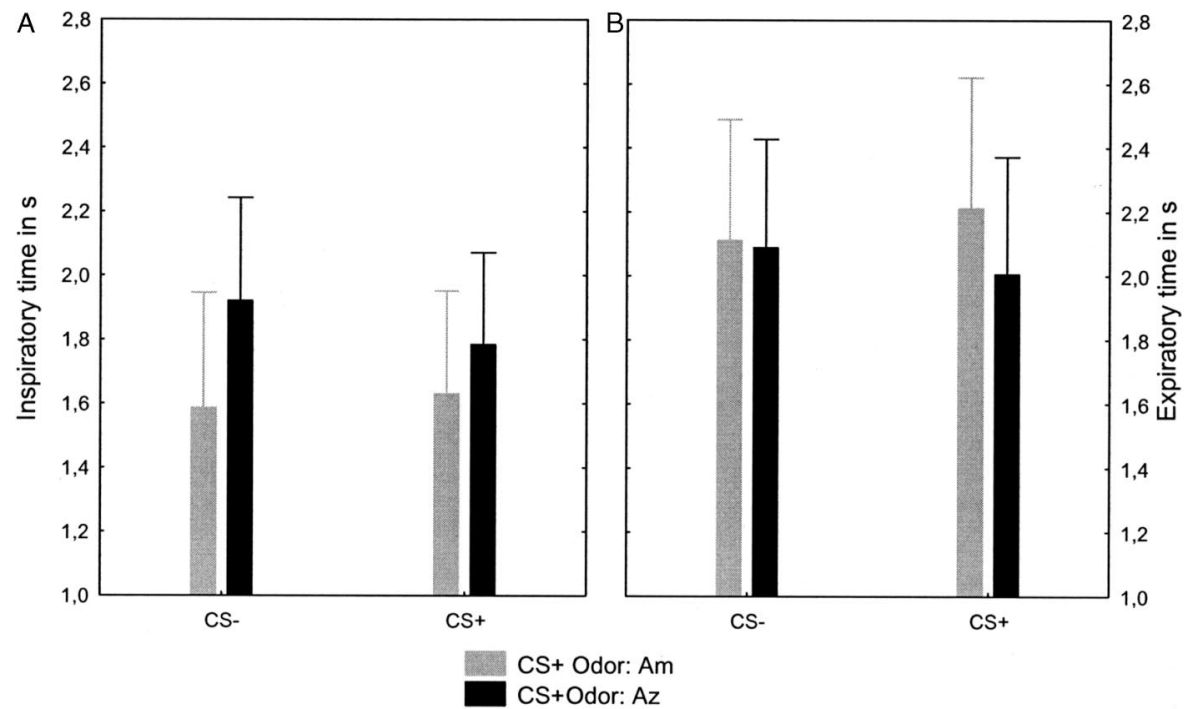

Figure 4. (A and B) Mean inspiratory and expiratory time during spontaneous breathing trials of the test phase for each CS + odor group. Bars denote $95 \%$ confidence intervals. 


\section{DISCUSSION}

The present study applied a differential conditioning paradigm with hypocapnic hyperventilation as an US and normocapnic hyperventilation as a within-subject control. Each type of trial was paired with an odor that served as a CS. Participants reported more lightheadedness during the hypocapnic compared with the normocapnic learning trials in the training phase. In a subsequent test phase without hypocapnic hyperventilation, lightheadedness showed up earlier and more "feeling unreal" was reported in response to the odor that had been paired with hypocapnic hyperventilation than to the odor previously paired with normocapnic hyperventilation. This finding indicates that NPC can be learned in response to odors as a result of prior hyperventilation in association with these odors. Because more pronounced learning of HYPERcapnic symptoms typically occurs in people scoring high on neuroticism (16), it would be interesting to see whether neuroticism moderates the presently observed effect as well.

For the training phase, difficult to interpret $\mathrm{CS}+$ odor $\times$ $\mathrm{CS} \times$ trial interactions were present for the online measures. These were likely caused by the relatively great variability in responsiveness to the 60 seconds of hyperventilation. Lightheadedness was very severe sometimes and it was hardly noticed other times. This is consistent with several observations indicating that the sensitivity of cerebral blood flow $(\mathrm{CBF})$ reactivity (percent decrease in CBF per percent decrease in $\mathrm{pCO}_{2}$ ) is variable. For example, a larger $\mathrm{CBF}$ reactivity was found in a protocol with sequentially increasing $\mathrm{pCO}_{2}$ values compared with a protocol with sequentially decreasing $\mathrm{pCO}_{2}$ values (34). Another study found that patients experiencing panic showed a larger CBF reactivity and reported more dizziness in response to hyperventilation compared with normal subjects (35). The latter finding suggests a role for fear/anxiety in interindividual differences in the lightheadedness response to hyperventilation (see also [36,37]). Further research should try to identify the critical variables that can predict the response.

For respiration, the learning effect in the test phase was dependent on the particular odor that had served as CS+. Participants who received ammonia as a $\mathrm{CS}+$ tended to breathe slower and had a higher $\mathrm{FETCO}_{2}$ during the CS + compared with CS - odor. This was reversed for participants for whom acetic acid had served as the $\mathrm{CS}+$ : their breathing was faster with lower $\mathrm{FETCO}_{2}$ 's during $\mathrm{CS}+$ compared with $\mathrm{CS}-$ trials of the test phase. One could only speculate what mechanism underlies this interaction. One such speculation is that participants differed in strategies to cope with the aversiveness of the situation. Further research should try to replicate the finding and try to distinguish between automatic breathing responses on the one hand and voluntary changes in breathing behavior aiming to cope with the aversiveness of the situation on the other hand.

Because the learning effects on NPC did not parallel those on respiratory behavior or $\mathrm{FETCO}_{2}$, it remains unclear what mechanism could have caused the NPC in the test phase. A first option is that symptom perception processes could fully account for the conditioning of NPC. Cognitive-perceptual models of symptom perception typically assume that somatic events may become represented in memory and that subsequent experiences, sharing common elements with the represented information, may activate this memory information automatically. The memory representations of previous somatic events would structure and bias the actual experience and/or the reporting of symptoms (38-42). In other words, whereas a first symptom episode may predominantly be determined by a physiological dysfunction, the nature and the relative dominance of the determinants of these symptoms may change across subsequent episodes.

Knowing that several systems in the body are sensitive to learning (e.g., the autonomic, immune, and endocrine systems [43-45]), an alternative explanation for the occurrence of NPC during the test phase of the current study implies the possibility of a learned cerebral vasoconstriction. In that scenario, the odor cue would become a trigger for cerebral vasoconstriction, even in the absence of hypocapnia in the test phase. This is a provocative, uninvestigated hypothesis with a great explanatory power for the association between stress/anxiety and NPC in general $(46,47)$. Stress-induced hyperventilation would be the trigger for reductions in CBF and NPC only initially, whereas cues related to stress may subsequently become CSs for reductions in $\mathrm{CBF}$ and NPC. Intermittent reinforcement through occasional episodes of hyperventilation could not only prevent the "extinction" of this learned association, but it might also contribute to further exacerbation of the problem. Indeed, although the effects found in the present study were rather small as a result of only three experiences of hypocapnic hyperventilation for 60 seconds, learning theory would predict much stronger effects with more trials and stronger hypocapnic stimuli, which are likely to be the case in real-life situations.

In summary, the present study showed that lightheadedness can be learned in response to an odor after that odor had been paired with hypocapnic hyperventilation. Although the mechanism underlying this learning effect is not clear yet, the findings enhance the potential value of a learning account to better understand NPC. Future research may apply transcranial Doppler sonography within the proposed learning paradigm to test whether a cerebral vasoconstrictive response can be acquired in response to odors.

\section{APPENDIX}

The rationale of the correction procedure assumes that the underestimation of $\mathrm{FETCO}_{2}$ is proportional to the percentage of regular room air that was being dispersed in the total amount of ventilation during a given trial. The procedure implied five steps:

1. The difference between the baseline trial preceding the test phase $\left(\mathrm{FETCO}_{2}\right.$ baseline test $)$ and the observed $\mathrm{FETCO}_{2}$ during the spontaneous breathing test trials $\left(\mathrm{FETCO}_{2} \mathrm{CS}+\right.$ obs and $\mathrm{FETCO}_{2 \mathrm{CS}-\text { obs }}$ ) was calculated for each participant. These differences will further be called observed difference scores of $\mathrm{FETCO}_{2}\left(\mathrm{dFETCO}_{2, \mathrm{Cs}+\text { obs }}\right.$ and $\left.\mathrm{dFETCO}_{2, \mathrm{Cs}-\mathrm{obs}}\right)$ : $\mathrm{dFETCO}_{2, \mathrm{CS}+\text { obs }}=\mathrm{FETCO}_{2}$ baseline test $-\mathrm{FETCO}_{2 \mathrm{CS}+\text { obs }}$ $\mathrm{dFETCO}_{2, \mathrm{Cs}-\text { obs }}=\mathrm{FETCO}_{2}$ baseline test $-\mathrm{FETCO}_{2 \mathrm{Cs}-\text { obs }}$

2. The percentage of dispersed regular air in the total ventilation of a given trial was calculated for both 
$(\mathrm{CS}+/ \mathrm{CS}-)$ spontaneous breathing trials of the test phase $\left(\%\right.$ disp $\mathrm{CS}_{+}$and $\%$ disp $\left.\mathrm{CS}_{\mathrm{C}-}\right)$. Because all trials lasted 1 minute, the total amount of ventilation equals the minute ventilation $\left(\mathrm{V}_{\mathrm{E}}=\mathrm{RR} \times \mathrm{Vi}\right)$.

$\%$ disp $\mathrm{CS}_{+}=2 / \mathrm{V}_{\mathrm{E}, \mathrm{CS}+}$ if ammonia was the $\mathrm{CS}+$ odor $=$ $4.5 / \mathrm{V}_{\mathrm{E}, \mathrm{CS}+}$ if acetic acid was the $\mathrm{CS}+$ odor

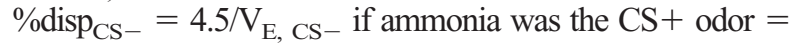
$2 / \mathrm{V}_{\mathrm{E}, \mathrm{CS}}-$ if acetic acid was the $\mathrm{CS}+$ odor

3. $\mathrm{dFETCO}_{2}, \mathrm{CS}+$ obs and $\mathrm{dFETCO}_{2}, \mathrm{Cs}-$ obs were predicted from $\%$ disp $_{\mathrm{CS}+}$ and $\% \mathrm{disp}_{\mathrm{CS}-}$ in a multiple regression analysis.

4. The intercept and $\mathrm{B}$ of the multiple regression analysis were used to predict the correction scores $\left(\mathrm{dFETCO}_{2}\right.$, predicted $)$ of all trials in which an odor was being administered.

5. The corrected $\mathrm{FETCO}_{2}$ 's, $\left(\mathrm{FETCO}_{2}\right.$, cor $)$ were calculated by adding these correction scores to the observed $\mathrm{FETCO}_{2}$ 's.

\section{REFERENCES}

1. Sorg BA. Multiple chemical sensitivity: potential role for neural sensitization. Crit Rev Neurobiol 1999;13:283-316.

2. Miller CS, Howard CM. Chemical sensitivity attributed to pesticide exposure versus remodeling. Arch Environ Health 1995;50:119-29.

3. Leznoff A, Binkley KE. Idiopathic environmental intolerances: results of challenge studies. Occup Med 2000;15:529-37.

4. Fiedler N, Kipen HM, DeLuca J, Kelly-McNeil K, Natelson B. A controlled comparison of multiple chemical sensitivities and chronic fatigue syndrome. Psychosom Med 1996;58:38-49.

5. Gibson PR, Elsm ANM, Ruding LA. Perceived treatment efficacy for conventional and alternative therapies reported by persons with multiple chemical sensitivity. Environ Health Perspect 2003;111:1498-504.

6. Gugliemi SR, Cox DJ, Spyker DA. Behavioral treatment of phobic avoidance in multiple chemical sensitivity. J Behav Ther Exp Psychiatry 1994;25:197-209.

7. Lehrer PM. Psychophysiological hypotheses regarding multiple chemical sensitivity syndrome. Environ Health Perspect 1997;105(suppl):479-83.

8. Van den Bergh O, Devriese S, Winters W, Eelen P, Veulemans H, Nemery B, Van de Woestijne KP. Acquiring symptoms in response to odors: a learning perspective on multiple chemical sensitivity. In: Sorg B, Bell I, eds. The Role of Neural Plasticity in Chemical Intolerance. Ann N Y Acad Sci 2001;933:278-90

9. Miller CS. Chemical Sensitivity: history and phenomenology. Toxicol Health 1994;10:253-76.

10. Sparks, PJ. Idiopathic environmental intolerances: overview. Occup Med 2000;15:497-510.

11. Van den Bergh O, Kempynck PJ, Van de Woestijne KP, Baeyens F, Eelen P. Respiratory learning and somatic complaints: a conditioning approach using $\mathrm{CO}_{2}$-inhalation. Behav Res Ther 1995;5:517-27.

12. Van den Bergh O, Stegen K, Van de Woestijne KP. Learning to have psychosomatic complaints: conditioning of respiratory behavior and somatic complaints in psychosomatic patients. Psychosom Med 1997;59:13-23.

13. Graveling RA, Pilkington A, George JPK, Butler MP, Tannahill SN. A review of multiple chemical sensitivity. Occup Environ Med 1999;56:73-85.

14. Fiedler N, Giardiono N, Natelson B, Ottenweller JE, Weisel C, Lioy P, Lehrer P, Ohman-Strickland P, Kelly-McNeil K, Kipen H. Responses to controlled diesel vapor exposure among chemically sensitive Gulf War veterans. Psychosom Med 2004;66:588-98.

15. Leznoff A. Proactive challenges in patients with multiple chemical sensitivity. J Allergy Clin Immunol 1997;99:438-42.

16. Van den Bergh O, Winters W, Devriese S, Van Diest I. Learning subjective health complaints. Scand J Psychol 2002;43:147-52.

17. Gardner WN. The pathophysiology of hyperventilation disorders. Chest 1996;109:516-34.

18. Wessely S, Nimnuan C, Sharpe M. Functional somatic syndromes: one or many? Lancet 1999;354:936-9.

19. Han JN, Schepers R, Stegen K, Van den Bergh O, Van de Woestijne KP. Psychosomatic symptoms and breathing pattern. J Psychosom Res 2000; 49:319-33.
20. Van Diest I, Winters W, Devriese S, Vercamst E, Han JN, Van de Woestijne KP, Van den Bergh O. Hyperventilation beyond fight/flight: respiratory responses during emotional imagery. Psychophysiology 2001;38:961-8.

21. Van Diest I, Proot P, Van de Woestijne KP, Han JN, Devriese S, Winters W, Van den Bergh O. Critical conditions for hyperventilation responses: the role of autonomic response propositions during emotional imagery. Behav Modif 2001;25:621-39.

22. Poonai N, Antony MM, Binkley KE, Stenn P, Swinson RP, Corey P, Silverman FM, Tarlo SM. Carbon dioxide inhalation challenges in idiopathic environmental intolerance. J Allergy Clin Immunol 2000;105:358-63.

23. Hegel MT, Ferguson RJ. Psychophysiological assessment of respiratory function in panic disorder: evidence for a hyperventilation subtype. Psychosom Med 1997;59:224-30.

24. Gorman JM, Fyer MR, Goetz R, Askanazi J, Liebowitz MR, Fyer AJ, Kinney J, Klein DF. Ventilatory physiology of patients with panic disorder. Arch Gen Psychiatry 1988;45:31-9.

25. Wilhelm FH, Trabert W, Roth WT. Physiologic instability in panic disorder and generalized anxiety disorder. Biol Psychiatry 2001;49:596-605.

26. Roth WT, Wilhelm FH, Pettit D. Are current theories of panic falsifiable? Psychol Bull 2005;131:171-92.

27. Meuret AE, Wilhelm FH, Roth WT. Respiratory feedback for treating panic disorder. J Clin Psychol 2004;60:197-207.

28. Bisgard GE, Neubauer JA. Peripheral and central effects of hypoxia. In Dempsey JA, Pack AI, eds. Regulation of Breathing. New York: Marcel Dekker, Inc; 1994:617-68.

29. Jibiki I, Kurokawa K, Matsuda H, Fukushima T, Kinichi H. Widespread reduction of regional blood flow during hyperventilation-induced EEG slowing. Neuropsychobiology 1992;26:120-4.

30. Van Diest I, Stegen K, Van de Woestijne KP, Schippers N, Van den Bergh O. Hyperventilation and attention: effects of hypocapnia on performance in a Stroop task. Biol Psychol 2000;53:233-52.

31. Wientjes CJE, Grossman P. Overreactivity of the psyche or the soma? Interindividual associations between psychosomatic symptoms, anxiety, heart rate, and end-tidal partial carbon dioxide pressure. Psychosom Med 1994;56:533-40.

32. Bakeman R, McArthur D. Determining the power of multiple regression analyses both with and without repeated measures. Behav Res Methods Instrum Comput 1999;31:150-5.

33. Cohen J. Statistical Power Analysis for the Behavioral Sciences, 2nd ed. Hillsdale, NJ: Erlbaum; 1988.

34. Ide K, Eliasziw M, Poulin M. Relationship between middle cerebral artery blood velocity and end-tidal $\mathrm{PCO}_{2}$ in the hypocapnic-hypercapnic range in humans. J Appl Physiol 2003;95:129-37.

35. Ball S, Shekhar A. Basilar artery response to hyperventilation in panic disorder. Am J Psychiatry 1997;154:1603-4.

36. Mathew RJ, Wilson WH, Humphreys D, Lowe JV, Wiethe KE. Cerebral vasodilatation and vasoconstriction associated with acute anxiety. Biol Psychiatry 1997;41:782-95.

37. Owega A, Sabri O, Klingelhöhef J, Albers M. Cerebral blood flow velocity in untreated panic disorder patients: a transcranial Doppler ultrasonography study. Biol Psychiatry 2001;50:299-304.

38. Cioffi D. Beyond attentional strategies: a cognitive-perceptual model of somatic interpretation. Psychol Bull 1991;109:25-41.

39. Lang PJ, Cuthbert B, Melamed B. Cognition, emotion and illness. In: McHugh S, Vallis T, eds. Illness Behavior: A Multidisciplinary Model. New York: Plenum Press; 1986:239-52.

40. Leventhal H. Symptom reporting: Focus on process. In: McHugh S, Vallis T, eds. Illness Behavior: A Multidisciplinary Model. New York: Plenum Press; 1986:219-38.

41. Leventhal H, Leventhal EA. Affect, cognition and symptom perception. In: Chapman CR, Foley KM, eds. Current and Emerging Issues in Cancer Pain: Research and Practice. New York: Raven Press; 1993:153-73.

42. Pennebaker JW. The Psychology of Physical Symptoms. New York: Springer-Verlag; 1982.

43. Ax AF. Individual differences in autonomic learning: a quarter century of reflection. Int J Psychophysiol 1990;10:1-9.

44. Somjen GG. The missing error signal: regulation beyond negative feedback. News Physiol Sci 1992;7:184-5.

45. Siegel S, Kreutzer R. Pavlovian conditioning and multiple chemical sensitivity. Environ Health Perspect 1997;105(suppl):521-6.

46. Ihlebaek C, Eriksen H, Ursin H. Prevalence of subjective health complaints (SHC) in Norway. Scand J Public Health 2002;30:20-9.

47. Interian A, Gara M, Diaz-Martinez A, Warman M, Escobar J, Allen L, Manetti-Cusa J. The value of pseudoneurological symptoms for assessing psychopathology in primary care. Psychosom Med 2004;66:141-6. 